\title{
Students’ Attitudes and Success during My First Attempts at Flipping
}

\author{
Craig McBride \\ University of Washington Tacoma, United States
}

\begin{abstract}
This paper is a description of my experiences flipping undergraduate mathematics and statistics courses for the first two years with analysis of various tools and advice for any fellow novice flippers. This paper discusses ways to start small and build up to a completely flipped class over the span of a few terms with advice on what technology to use including software, hardware, and online Learning Management Systems (LMS) such as WebAssign and Pearson's My Lab \& Mastering. Students' academic performances as well as attitudinal data were collected and analyzed to see if flipping and/or the use of an LMS had a positive effect on learning and attitudes. Both performance and attitudes improved with flipping, but the LMS did not appear to effect grades.
\end{abstract}

\section{Introduction}

It has been almost two years since I tried flipping my first class, and if you are anything like I was before I began, you are both intrigued and reluctant. Intrigued because you have heard several accounts of how well flipping mathematics and statistics classes can work, but reluctant because you don't have the time to spend creating all of the videos and other materials necessary to try it in your own classes. I agree that the idea of prepping your classes all over again from the ground up and creating all new materials and videos sounds daunting, but what you may not already know is that it isn't necessary. If you are passionate about teaching, and you want to see your students perform better, then flipping the classroom is for you.

First of all, don't be afraid to start small. You don't have to do it all at once. Start by flipping just one chapter or even one lesson topic and then expand from there. Flipping doesn't have to include videos, and you can always use videos made by other people until you are ready to make your own. I started small with just PowerPoints and then expanded from there, and I will share my experiences with you so you don't have to reinvent the wheel. Educational fads come and go, but this is definitely one bandwagon you WANT to jump on because the differences you will see in your students' attitudes and achievement will exceed all expectations.

\section{The journey begins}

My reasoning behind trying the experiment of "flipping" my classes was to achieve four things. First, I wanted to cover more material. Second, I wanted to engage the students more in class by "lecturing" less. Third, I wanted the students to have an enjoyable experience with mathematics since most students were non-math/science majors with preconceived prejudices against math. Fourth, I was hoping their grades and pass rates would increase. I had read articles [3] - [14] and heard speakers [1] \& [2] at the 2013 Joint Mathematics Meetings extoll the virtues of flipping classrooms and how much success they had seen from their trials. I always wanted to try it, but I just didn't have the time to create all of the videos and other materials that were (in my opinion) necessary to successfully flip a mathematics classroom, so I decided to start slowly and see what worked.

My adventures with flipping began informally in the spring of 2013. It was during the preceding fall semester that I began to consider flipping on a small scale because the current (more traditional) mode of instruction just wasn't working well. The students were doing adequately well with the material (some far better or worse than others), but it felt so lifeless. I had to spend most of each class lecturing about material while students frantically took notes or just zoned out altogether. I would elicit laughs when I could and pry answers out of them as often as possible, but they never seemed fully engaged with the material. So, over the winter break, I decide to take the plunge!

\subsection{Initial class format}

The class was flipped from the beginning of the term utilizing PowerPoints as the major mode of delivery for lecture material and supplemented with applets, online resources, and video lessons and tutorials whenever possible. Most resources (including videos) were from the book or found on the internet. Students were expected to read through the PowerPoints on their own or in groups outside of 
class, and classes met 4 days per week (Mon, Tue, Thu, Fri) for 50 minutes each day over a 16 week semester. Class time was devoted to answering some guided questions, homework questions, and working through examples of the techniques discussed in the PowerPoints in groups using real world data. Additionally, I would use class time to present "mini-lectures" (10-20 minutes) whenever the subject matter required it.

A typical class consisted of five minutes asking probing questions about the out-of-class material to gauge if they "got it" or not, always being prepared to lecture on every topic if needed. Then, we would spend five to ten minutes doing a few examples (1020 if it seemed necessary). The remaining time was spent working in groups on more examples. This allowed me time each day to move around the room utilizing differentiated teaching while working with students and groups one-on-one answering questions and providing personalized formative feedback.

I used probing questions to get students to describe their thought processes and statistical reasoning skills. By requiring them to continuously "explain" their results verbally in class, they were forced to understand their results rather than merely being able to get a number from a calculator. Quiz and test questions also required students to "explain and interpret” their results using complete sentences, so everything built on the verbal explanations they practiced in class. Most days, the students did group work consisting of a few questions that modeled the material being discussed.

\section{Introduction of the online tools}

The flipping experiment was going so well that I decided to try adding another element halfway through the semester. Just prior to the midterm, I introduced students to the publisher's online learning tool MyStatsLab. If you haven't used MyStatsLab or MyMathLab (now called MyLab \& Mastering), it is a brilliant learning tool that allows your students to practice homework questions over and over. It also comes with built-in multimedia tools that help guide them through any questions with the option to still ask you questions via email with a link to the exact item they are attempting. You can also assign quizzes and tests and keep track of grades and attendance/activity. It is similar to (and in my opinion far superior to) other tools such as WebAssign, WeBWork, and Thinkwell.

Since this was a "pilot program" idea, I was able to get free access codes (normally around \$100 each) for my students from my textbook representative. Setting up the Learning Management System (LMS) took about the same time as the PowerPoints. Even though it was my first time working with MyStatsLab, I was still able to create a serviceable course shell with homework and quizzes for every section in just a few days after watching some YouTube videos and reading through the FAQs. Some books even come with ready-to-use course shells with all of the homework assignments, quizzes, and tests already created for you. Even if you have to build one from scratch, the interface is easy and you will pick it up quickly.

Students were asked to do their homework and quizzes for the remainder of the term online. Since the use of the LMS was not in my syllabus, I did not feel it was appropriate to force this change on them, so I made use of the LMS voluntary, and nine of the 39 students opted to continue working out of the book for homework and quizzes. The last five chapters covered (8-12) were done online, and the midway split allowed me to analyze the effectiveness of the LMS by comparing scores before and after implementation along with the 9 who opted out acting as a control group. After gauging both student performance and their attitudes about the tool, I could decide if I wanted to continue using it with future courses. The results were promising, so I decided to use it whenever I could in the future.

\section{Analyzing the impact of the LMS}

My first foray into the world of flipping allowed me to look at the effectiveness of flipping a college level introductory statistics course. Additionally, I wanted to determine if the use of the LMS had a measureable effect on their grades. So, I looked at their scores on various exams as well as their final course grades.

\subsection{Sample \& setting}

The sample consisted of 20 female and 19 male mostly freshman $(\mathrm{N}=21)$ and sophomore $(\mathrm{N}=9)$ students in a highly selective private liberal arts college located in the Pacific Northwest. 13 students had business or science-related majors, seven had liberal arts majors, and 19 were undecided. Of the 39 students in the two sections, 22 participated fully in the online version and nine opted out of all online tools. Two students did homework online but not quizzes, while two different students did the opposite. Two students ended up switching back to the book for homework after a few chapters, while two different students switched back to paper quizzes. One student switched back to both paper homework and quizzes.

The college had 2,600 students enrolled (43\% male) from 44 states and 16 countries. $76 \%$ of the 
student body came from out-of-state. 99\% of the tenure-line faculty held a doctorate or equivalent, and $93 \%$ of the faculty was full time. The studentfaculty ratio was 12 to 1 , and the mathematics department had 13 (all full time) faculty members. Every classroom had a podium and lectern computer with a ceiling-mounted digital projector. The set up was perfect because the screens were all located next to the chalkboards rather than in front of them, which allowed for the full use of the boards while projecting something on the screen.

\subsection{Analysis of grades}

The first data I analyzed were their total course grades. Table 1 shows the breakdown of letter grades and overall course averages for all three groups. The "all” group represents the 22 students who did all of their work online for the entire experiment. The "none" group consists of the nine students who did not try doing any work online. The "some" group consists of any student that did only homework or only quizzes online or switched at all during the experiment. Preliminary examination of the three group means shows little difference, and the one-way ANOVA confirmed that there was no significant difference in the three means $(F=3.26, p=0.74)$. Next I ran a chi-square analysis of the distribution of letter grades to see if they differed by group. This result also indicated no difference $\left(\chi^{2}=2.60, p=\right.$ 0.63 ). Over $20 \%$ of the cells have expected counts less than 5 , so the result is suspect, but observation of the relative frequencies shows little difference in the A's and B's.

Table 1. Course grades for all three groups

\begin{tabular}{lccccc}
\hline Group & N & Mean & A's & B's & C's \\
\hline All & 22 & 88.44 & $13(59 \%)$ & $6(27 \%)$ & $3(14 \%)$ \\
None & 9 & 88.78 & $6(67 \%)$ & $3(33 \%)$ & 0 \\
Some & 8 & 90.73 & $5(63 \%)$ & $3(38 \%)$ & 0 \\
\hline
\end{tabular}

Results were similar when comparing the final exam grades $(\mathrm{F}=0.31, \mathrm{p}=0.73)$ and the distribution of letter grades $\left(\chi^{2}=4.96, \mathrm{p}=0.29\right)$ for the three groups. The grades $(\mathrm{F}=0.31, \mathrm{p}=0.73)$ and the distribution of letter grades $\left(\chi^{2}=4.96, \mathrm{p}=0.29\right)$ for exam 3 also showed no significant difference. I looked at exam 3 separately because it was the only exam to occur after the introduction of the LMS. The average score $(\mathrm{F}=0.19, \mathrm{p}=0.83)$ and distribution of letter grades $\left(\chi^{2}=6.29, \mathrm{p}=0.18\right)$ on the four quizzes that were taken after the introduction of the online tools showed slightly more parity. However, none of the scores or distribution of letter grades differed significantly across the three groups.
Lastly, I wanted to test the claim that students will cheat if given the chance to do quizzes online outside of class. I am not naive enough to think that some students won't cheat to some degree if given the chance, but I wanted to see if it would actually impact their grades. My quizzes are closed notes and closed book. Students are given formula sheets and any necessary tables (normal distribution or T-table etc.) 25 students did all four of the last quizzes online, nine did them all on paper and four did a combination of both. If online students cheat, then I should see a difference in scores between the online and in-class paper groups.

In order to control for the fact that the last four quizzes are harder than the first eight and any variations within the groups as much as possible, I looked at the difference between each students' average quiz grade for both parts. First, I calculated the average quiz grade for each student for the first eight quizzes and the last four. I also calculated a "trimmed" mean where I dropped the lowest score from each set of grades as students were allowed to drop their lowest quiz score. This meant that many students had a zero score in one of the two sets of quizzes, and I didn't want those scores to possibly affect the analyses. After I computed the means of both categories, I computed a difference score for each student by taking the mean of the last four quizzes minus the mean of the first eight. This meant that a negative difference score indicated that the student did worse on the last four quizzes (more common). Lastly, I computed a two-sample T-test comparing the difference scores of the two groups (paper \& online). The results do not support the claim that the groups had significant differences in quiz means $(\mathrm{T}=-0.21, \mathrm{p}=0.836)$ or trimmed means ( $\mathrm{T}=-0.57, \mathrm{p}=0.577)$. In fact, you can see from Table 2 that the group that did their quizzes online actually had averages that went down MORE than the group that did them on paper.

Table 2. Quiz score differences by groups

\begin{tabular}{lccccc}
\hline Group & N & Mean & Var & Trim & Var \\
\hline Online & 25 & -7.82 & 262.29 & -6.58 & 175.28 \\
Paper & 9 & -6.61 & 227.72 & -4.14 & 115.65 \\
\hline
\end{tabular}

This, in my opinion, is a good thing. If there was a significant improvement in online quiz scores, it would support the theory that students cheat more with online tests. If the online quiz grades had been significantly lower, it may have indicated that the LMS was hindering their learning or that they were struggling with the interface. If the online group had done worse on the paper final or in the course in general, it would imply that they didn't learn as well with the use of the LMS. By having similar results 
across all metrics, it means we are free to use an LMS as a learning tool without fear that it will either hinder learning or artificially inflate scores.

\subsection{Benefits of the LMS}

If the LMS doesn't appear to have an effect on student performance, then why should we use it? Well, in my opinion, there are two major reasons why using the LMS is still beneficial. First, it frees up valuable class time. Second, and most importantly in my opinion, it provides students with immediate formative feedback while allowing them to easily practice skills.

The amount of time spent in class collecting homework and handing it back was eliminated completely. That may seem small, but it adds up. Also, the students had fewer homework questions. Thus, I didn't have to dedicate as much time in class to answering them. Quizzes are graded for you, so you have more time to spend developing lesson plans and fun activities for class. Since students are able to review their own quizzes, I no longer needed to devote class time to going over the answers.

The students are encouraged to review their own quizzes to see what they did incorrectly and alert me if they feel they deserve more points. One of the major complaints from students is that the system tends to grade too strictly. It would mark the response " 0.5 " incorrect because it asked for the answer to be a fraction or " 1.25 " incorrect because it wanted it rounded to one decimal place. This issue led to lots of frustration and dissatisfaction initially with the quizzes. However, I found it to be an advantage because it motivated students to review all of their incorrect answers looking for those that were marked wrong incorrectly and deserved more points. This allowed them to learn from their own mistakes far more effectively than just having an answer key because they can then practice similar questions in their homework section. Each question on the quiz or test has an item number in the top right corner which identifies which homework question it is. This allows the student to then return to the homework assignment and re-do the ones they missed. The system will continue to generate new sets of data or different numbers for a question, so they can practice questions until they feel they have mastered the concept.

This ability to practice homework questions over and over again while getting instant formative feedback is the biggest benefit of the LMS. Not only does it tell them they got an answer incorrect, but it is also intelligent enough to offer tailored advice as to what they might be doing wrong. As an educator, I feel this feedback is invaluable and logistically impossible in a paper and pencil homework situation. By doing the online work, students were able to practice the mechanics of getting the correct answer as many times as they felt was necessary outside of class either alone or in groups (doing homework together was encouraged), while class time could be better utilized repairing misconceptions and learning how to interpret their results and thus develop a deeper understanding.

\section{Initial student attitudes}

The quantitative data showed no difference in quiz scores, test scores or final course grades for those students who used the LMS. However, the qualitative data showed a significant improvement in student attitudes. Most Students stated they enjoyed the flipped experience during both informal and formal surveys. I collected anonymous survey responses both during and after the term. These results along with unsolicited responses both verbally and via email suggest that most students enjoyed the class and many of the non-science majors stated learning more and enjoying the class more than any other mathematics class. When asked how they felt the flipped format compared to the more traditional lecture style format on the end of term anonymous survey, one of my more eloquent students commented thusly:

I firmly believe that class time is poorly spent learning new material. To do so would be to degrade a highly skilled professor to nothing more than an interactive text book and-even more importantly- to ignore the contribution that fellow students can have on an individual's learning. Rather, the "flipped" class allowed students who struggled with the material to come to class ready to advance their understanding, allowed students with some grasp of the material to reinforce their understanding by participating with their classmates, and gave an opportunity for students who had mastered the material to investigate beyond the narrower constrains of the text book itself. (Anonymous)

I couldn't have said it better myself! Because this was a new experience for both me and my students, I would regularly gauge their attitudes by asking how they were doing.

Flipping allowed me to cover far more material than my colleagues and I worried that the pace was too fast for the students. I covered four chapters more than I had the previous term, and while other classes stopped at simple linear regression, we continued on and covered multiple regression, nonlinear regression, logistic regression, chi square 
goodness-of-fit, chi square contingency tables, one way ANOVA, and two way ANOVA.

I was concerned that we might be going too fast, so I asked for their opinions on the pace of the course both at the midterm before we introduced the LMS (PRE) and at the end of the course (POST). The survey question was:

Please rate the pace of the class from 1 to 5

( 1 = way too slow, 2 = kind of too slow,

3 = just right, $4=$ kind of too fast, $5=$ way

too fast) - You can use decimals etc.

Figure 1 displays the results of both surveys. 23 students answered the midterm survey with a mean response of 3.43, while 20 students answered the end of course survey with a mean response of 3.08. The proportion of students who thought we were going too fast decreased after introducing the LMS.

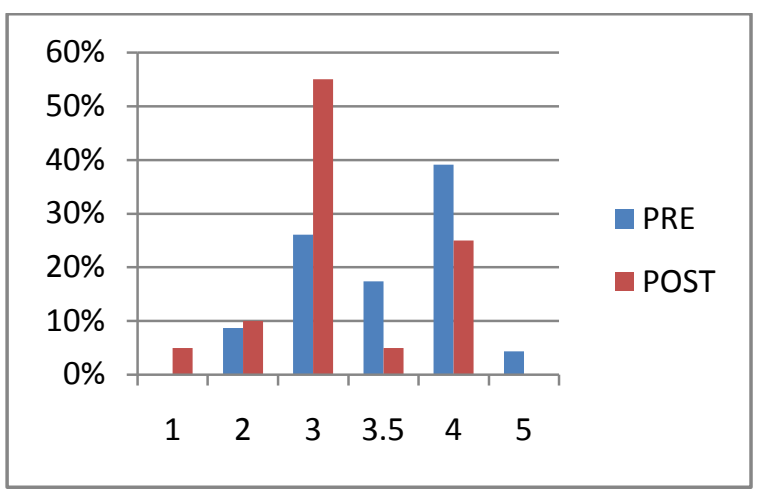

Figure 1. Class pace

After introducing the LMS, the proportion of students who felt the pace was "just right" went from $26 \%$ to $55 \%$ while those who felt the pace was too fast (answered 4 or 5 ) fell from $43 \%$ to $25 \%$. This may be attributed more to the students becoming more comfortable with the flipped format, but regardless of the cause, the survey results along with my own informal surveying of asking for students' opinions during class and in office hours suggests that the majority of students felt the pace was okay. I even had some students come into class saying that friends of theirs in other classes were several weeks behind us in the material. I asked if they felt we were going too fast, and they all said "no" and they were more surprised at how slow the other classes were going.

\section{Phase two - other peoples' videos}

After successfully flipping my first undergraduate mathematics class, I decided to try it again in a completely different setting to see if it could still be successful. The next fall, I began teaching at a large state university satellite campus that caters to non- traditional students. Classes typically met twice a week for 125 minutes each day during a ten week quarter term. My first assignment was two back-toback Calculus 1 classes, and the thought of having to "lecture" for nearly 4 hours straight made my throat hurt.

During the successful trials of the previous year, I purchased a Wacom tablet, a high-quality Logitech USB headset microphone, and Camtasia recording software. I started small by merely posting video solutions to homework questions and then graduated to making short instructional videos for some of the more confusing subjects in the statistics class. However, time constraints did not allow me to create videos for my calculus class so I had to rely on other resources.

This time, I had no PowerPoints and no videos of my own, so I turned to YouTube for help. I found so many excellent videos on every subject we were going to cover that I was able to compile a list of five to eight video recommendations for every topic. I created a Google Doc (Figure 2) with the title of each chapter and hyperlinks to each video with the title and author listed. I tried to find different authors for each topic while using videos from the same people repeatedly when they turned out to be particularly good teachers. By listing the author's name for each video and offering multiple video choices for each topic, students could watch videos presented by the people they tended to like the best.

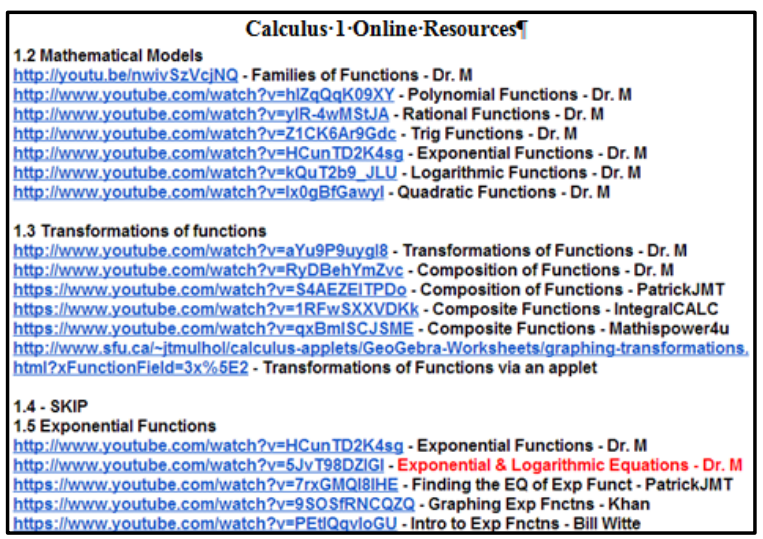

Figure 2. Calc 1 Google Doc

I modeled my overall class structure after the statistics class with more time allocated to each class phase (homework questions, group work, etc.) Students were expected to watch at least one video and begin working on their homework BEFORE class each day. 


\subsection{Updated class structure}

We began each day with 30 minutes of answering homework questions and discussing the major topics of the section. They would then take their daily Concept Check (CC) on the material. Each CC contained two to five questions modeled on the homework. They were intended to highlight the major topics and techniques of each section covered. Students were allowed to use their books and notes on the CCs, so care was taken to make sure that each question was not part of their actual homework assignment nor was it any odd numbered questions without first changing numbers and details. Students were given 30 minutes to finish each CC and they brought their answers to me as they finished so I could quickly grade them and offer instant formative assessment and feedback.

If it appeared that a majority were struggling with the same question, the class would discuss that question and a few similar examples after the CCs were all done. The remaining time was spent working on homework or a worksheet of sample questions in groups or on their own. Homework and quizzes were done online using a different LMS (WebAssign) while all exams were given in class on paper.

Although I did not have any control group or experience teaching the course the "traditional" way in this new setting, I was able to compare my students' results with other sections of Calculus 1 offered at the same school over the past few years. My pass rate was higher, and the overall average grade was also higher. Additionally, student attitudes seemed better than what my colleagues reported in their traditional classes. End of term student evaluations revealed that most favored the new format, and my classes for the next term quickly amassed long wait lists.

\section{Fully flipped with my own videos}

With the time afforded me over the winter break, I was able to take flipping to the next level with my next three classes by creating a full set of my own videos. In the winter term, I had two sections of introductory statistics and one section of precalculus. Along with Calculus 1, these were the three worst courses in our department in terms of non-pass rates.

\subsection{Historically low pass rates}

Precalculus was particularly bad with drop/fail rates routinely at $20-35 \%$ and sometimes as high as $50 \%$. The main problem with all three courses (and particularly precalculus) was the sheer volume of material that needed to be covered in such a short amount of time. It was bad enough that we were already short-changed by being on a quarter system and only meeting for 10 weeks instead of the standard 15-16 weeks that most semester schools have. However, on top of that, classes that routinely met five times per week for 50 minutes each day at other schools were now being taught only two days each week for 125 minutes each day. In order to cover the same amount of material in this shortened timeframe, we have to cover two or even three sections every day.

Our campus caters to non-traditional and foreign exchange students, so most are older than the usual college-aged student. They normally work full time or are in the military, and their educational backgrounds are more diverse than most universities. The range of mathematics abilities in a precalculus class can span everything from those who can't add fractions to those who are ready for calculus, with most on the lower end of the scale. Lecturing to these types of students for two hours and trying to get through so much material in a short amount of time just doesn't work and it was no wonder that nearly a third would drop or fail ever term.

\subsection{Flipping to the rescue}

My previous (limited) experience with flipping taught me that it was possible to cover more material in less time, so it seemed like it would be a perfect fit for this academic setting. Since I already had so many statistics materials from my previous school, I was able to start creating more videos for both statistics and precalculus.

By now, I had gotten pretty good at creating lecture videos using Camtasia, PowerPoint, a Wacom tablet, and various online tools. Texas Instruments provides a free TI-83 graphing calculator emulator, so I am able to bring it up on the screen and show students how to input the data and conduct the necessary analyses using their calculators as I talk about various topics. Additionally, there are online statistical tools that allow students to perform fairly robust analyses with ease, which allows us more time to discuss the results and how to interpret them correctly. Since Camtasia records everything on your screen, you can use any online tools you want and the students can see how to use them as you work through a question or demonstrate a technique.

Luckily for me, the precalculus book came with a great set of PowerPoints that I was able to edit and augment easily. By keeping my original statistics lectures organized by topic rather than by section or chapter, I was able to re-use everything even with a completely different textbook. That little tip alone saves me the time and hassle of having to re-record 
everything whenever I change textbooks. With most of the statistics work done already, I could devote enough time to completing my entire library of statistics videos while building from scratch a set of precalculus videos.

One of the nice features of Camtasia is how seamlessly it integrates with YouTube. I am able to edit and then upload my videos directly to my own YouTube channel where my students (and anyone else) can watch them. Rather than requiring my students to hunt around through hundreds of videos on my channel, I create simple Google Docs (Figure 3) with hyperlinks to each video placed in a schedule that I then publish to Canvas.

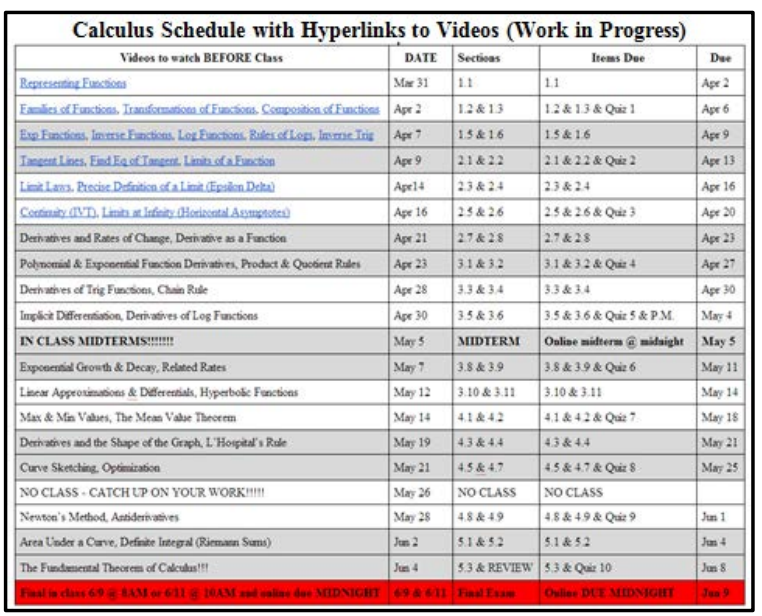

Figure 3. Calc 1 "live" schedule

Using Google Docs allows me to make edits and changes to the "live" document without having to worry about updating it on Canvas. Because the file is embedded, it gets updated automatically. Since my videos were a work in progress, this auto-updating feature was essential. As long as I stayed a week or two ahead of my students, I could take my time and create good videos. I could then paste the new links in the Google Doc, and the new links would appear on the document in Canvas. It also allowed me the time to answer homework questions by posting a quick video solution rather than trying to type out a solution over email, which we all know is VERY difficult with mathematics symbols and formulas.

By the end of the winter term, flipping had become easy. The students were used to the format and I was able to crank out videos quickly and easily. Each day before class, I would log into the LMS to see how they were doing on their homework and it was so shocking to see how many students had regularly done most if not ALL of their homework before we had even begun to discuss it in class. The students loved the format, and they were thriving in this setting.
Only four of 60 precalculus students failed mainly because all four had just stopped coming to class. All 30 of the statistics students passed, and the class averages for all three were significantly better than the other sections. I began to worry that I was making it too easy to get a good grade in my class because these kinds of results seemed too good to be true. Currently, we are in the process of tracking my students to see how they perform in subsequent courses. We have data going back for several years on all students in our mathematics classes and we hope to analyze the data in the near future to see if these students continue to perform well in other classes. Although I did not have time to administer my own set of surveys, student evaluations showed that once again the students liked the flipping model and word was quickly spreading around campus.

\section{Student response}

Last spring, I taught two sections of Calculus 1 and one section of precalculus. I was supposed to only teach two classes, but after more than 38 students had requested to be waitlisted in my first section of calculus, we had to offer the second section. The courses went well and the student attitudes seemed to be so much better than in other classes. I continue to elicit feedback from my students via anonymous online surveys and the university-conducted student evaluations. The responses are predominantly very positive.

\subsection{Student evaluation comments}

The university conducts official student evaluations at the end of each class. One question asks students what aspects of the class contributed most to their learning. The videos were popular. "The online lecture videos [were] very helpful. Being able to rewind and pause [while] I take notes" - Winter2014Stats. "The videos the instructor made [were] very helpful and whenever I was confused about a problem, I could refer back to that video for help" - Winter2014Stats. "The videos are great. If I have trouble I can re-watch over and over." Spring2014Calc1. Comments like these show up on every evaluation summary report.

In addition to the videos, many students think the online homework system contributed to their learning. "MyMathLab for homework and the ability to ask questions and see examples in class" Winter2014Precalc. "The 'View an Example' button on The Pearson website is a BIG help for me" Winter2014Precalc. "Homework helped me the most because if I had a question it could be answered right away" - Spring2014Calc1. "The online homework 
was very helpful, being able to repeat a question until it is correct definitely helped my grade" Spring2014Calc1. "The best part was unlimited attempts at online homework. Without the stress of getting the answer right or losing points, I could focus on the actual concepts and I learned a lot more than I ever did" - Summer2014Precalc. It should be noted that the calculus classes use the WebAssign online system from a different publisher, and the response is equally positive.

Many students feel the overall structure of the course and the flipping in general contributes most to their learning. "The PowerPoints were helpful, and I don't think it would have been easy to understand the concepts in class without reading them, but I definitely don't think it would have been easy to understand the PowerPoints without class time" Fall2013Calc1. "The flipped method of teaching. I always had teacher help/examples online in his videos and I had class time to ask him questions for homework. It was the best use of time and most effective way I have ever been taught math" Winter2014Precalc. "The in class lectures after watching the videos before class really helps drive home points that I may have missed previously" Winter2014Precalc. "I like the flipped classroom idea because it allows everyone to go at their own pace and come in the day of class with questions that they may have" - Winter2014Stats.

When asked if they felt the class was intellectually stimulating, I got two of my favorite responses of all time. "Yes. He did the impossible. He made me like math. It's awesome” Winter2014Precalc.

EVERY day of this course, I found myself mentally exhausted by the time I left this class. Prof. McBride is such an intelligent, engaging instructor that his lessons absolutely locked on to my attention forcing my brain to attempt to keep pace with his. There was no "white space" through the quarter and from the time I took my seat until the time I packed up to leave, my mind was fully engaged with the subject material. I can't say that about any other course in my three years at UWT - Spring2014Precalc

These types of comments keep you going!

\subsection{Student evaluation scores}

In addition to mostly wonderful feedback, I was also getting exceptionally high marks on the student evaluations. A total of 187 students from nine different courses over the last year and a half completed the evaluations. Among other questions, students were asked to rate the course as a whole
(4.73), the course content (4.64), and the relevance and usefulness of the course content (4.64) on a 5point scale from excellent (5) to very poor (0). In reference to the course as a whole, $67.36 \%$ ranked the courses as excellent, $23.52 \%$ ranked the courses as very good, $5.39 \%$ ranked the courses as good, and only $3.73 \%$ ranked the courses as fair or poor.

Of course, there are students who do not like the format or my teaching style, but they are a VERY small percentage; much smaller than in other nonflipped courses. Demand for my classes continues to grow and students regularly ask the administration what classes I am teaching next term or when I will be teaching a certain subject. I am hoping that future analyses of their performances will show that they are in fact learning the material better and thus performing better in future mathematics and science classes.

\section{Conclusion}

I now have a complete set of videos for Statistics, Precalculus, and Calculus 1. I created all of the PowerPoint slides and videos based on topics rather than book chapters so that they will remain relevant and useful regardless of textbook changes. This means that some chapters may require multiple videos while others only one. I have heard some experienced flippers say that videos need to be kept short (under 5-10 minutes), but my own experience is that students prefer less videos even if that means that each one is longer. Because technology makes it so easy for them skip around in a video, I feel that the psychological impact of seeing a list of ten videos to watch is far worse than having to watch one 30-minute long video.

My advice to anyone considering flipping their class (especially a mathematics class) is to go for it. Don't be afraid to take baby steps. I understand how daunting it can feel to think about having to create all of the videos and other materials, but you don't have to do it all at once. In fact, you don't have to do it at all if you can find the appropriate materials from other people. There is no reason why we all have to continuously reinvent the wheel ourselves when we can use each other's videos and resources. All of my videos are free to use and available on my YouTube channel (DrCraigMcBridePhD) as are thousands of other quality videos. You just have to take the time to watch them to see that they cover the correct things. Links to my videos, publications and other teaching materials are also available on my website [15].

I always create a discussion board where students can post links to videos or resources that they find and I usually award small amounts of extra credit to 
anyone who finds really good ones. Your students already spend thousands of hours each year watching videos online, so let them help you find good ones.

Look for resources from your textbook, the publisher, or other books. Most texts come with Powerpoints and other resources like links to applets etc. Most items are free to use with no copyright issues, and those that are copyright protected can either be allowed for use by the publisher if you ask or just use them as inspiration for your own items.

Wacom tablets are now under \$50, and most schools have site licenses for Camtasia, Tegrity, Panopto, or similar lecture capturing software. Jing is available free, but it only records in five minute increments. Simple tips like formatting all of your slides to 13.3 ” by 7.5 ” (1280 x 720) makes the video fit perfectly on YouTube.

Online learning management systems like WebAssign, MyMathLab, MyStatsLab, and others may seem expensive for your students with access codes costing anywhere from $\$ 65$ to $\$ 125$, but when you consider that they all come with a free copy of the eBook and most students are fine using it, it can actually end up costing them less.

The online books also come with embedded multimedia tools. As students are reading through the chapter, they can click on an icon and launch a video or an applet that will help them investigate the concept. Many of the homework problems offer video or written solutions and tutorials as well. Additionally, there are several websites with free applets and materials - just start looking.

Make sure and require attendance or give daily quizzes. I tried flipping an eight week evening class once without having the quizzes, and as soon as the students figured out the videos were all online, they stopped coming to class. Out of 15 students only 3-4 would show up each night. Other teachers have expressed similar concerns or have seen similar problems where students end up treating the course like an online course since they can get all of the materials outside of the classroom. So you must provide incentives for coming to class. They don't realize how much they learn from being in the classroom with other students asking questions and discussing the topics, so do whatever is necessary to make sure they attend class.

Flipping can seem like a lot of work up front and it is if you start from scratch and try to do it all at once, but you don't have to do that. Start slow - flip just one chapter or one topic or one lesson. Use other materials and videos and let other people do the heavy lifting for you until you feel comfortable enough making your own materials. As educators we all know that an ideal student would read or at least skim through the chapter material PRIOR to class, so that we could just hit the highlights and then have more time to work examples and dive deeper into the material. As educators we also know that students RARELY read the book (especially mathematics books). Flipping gets them to gain the same level of insight they would from reading the book by giving them the material in a mode they are more accustomed to using. PowerPoints, videos, applets, and other online tools are things they see and use every day and are thus far more willing to spend time utilizing. I have seen an amazing transformation in my students over a short period of time, and you too will be amazed at how much better your students do and how much more engaged they are in class.

\section{References}

[1] Abbasian, R. O., \& Sieben, J.T. (2013, January 9). A Brief tutorial on building a "flipped" classroom. Paper presented at the 2013 Joint Mathematics Meetings, San Diego, CA. Abstract retrieved from http://jointmathematics meetings.org/amsmtgs/2141_abstracts/1086-vf-2336.pdf

[2] Aragon, R. D., Brown, T., \& Bell, M. (2013, January 9). Flipping a college algebra classroom. Paper presented at the 2013 Joint Mathematics Meetings, San Diego, CA. Abstract retrieved from http://jointmathematicsmeetings .org/ amsmtgs/2141_abstracts/1086-h1-406.pdf

[3] Baker, Celia. (2012, November 25). Flipped classrooms: Turning learning upside down: Trend of "flipping classrooms" helps teachers to personalize education. Deseret News. Retrieved from http://www.deseretnews.com/ article/765616415/Flipped-classrooms-Turning-learningupside-down.html?pg=all

[4] Bergmann, J. \& Sams, A. (2012). Flip Your Classroom: Reach Every Student in Every Class Every Day. International Society for Technology in Education.

[5] Berrett, D. (2012, February 19). How 'flipping' the classroom can improve the traditional lecture. The Chronicle of Higher Education. Retrieved from http://chronicle.com/ article/How-Flipping-theClassroom/130857/

[6] Fulton, K. (2012, April). Inside the flipped classroom. The Journal. Retrieved from http://thejournal.com/articles/ 2012/04/11/the-flipped-classroom.aspx

[7] Gojak, L. (2012, October). To Flip or Not to Flip: That is Not the Question! National Council of Teachers of Mathematics. Retrieved from http://www.nctm.org/about/ content.aspx?id=34585

[8] Gorman, M. (2012, July 18). Flipping the classroom...a goldmine of research and resources keep you on your feet. Retrieved from http://21centuryedtech.wordpress.com/ 
[9] Green, G. (2012, July). The Flipped Classroom and School Approach: Clintondale High School. Presented at the annual Building Learning Communities Education Conference, Boston, MA. Retrieved from http://2012.blc conference.com/documents/flipped-classroom-schoolapproach.pdf

[10] King, J. (2011, September 29). Flipped instruction. Retrieved from: http://blogs.bcbe.org/blogit/2011/09/29/ flipped-instruction/

[11] November, A. \& Mull, B. (2012, March 29). Flipped learning: A response to five common criticisms. Retrieved from: http://novemberlearning.com/assets/flipped-learninga-response-to-five-common-criticisms.pdf

[12] Pfeiffer, K. (2012, February 17). The flipped classroom: Teaching and learning in the 21st century. Retrieved from: http://info.lecturetools.com/blog/?Tag= Flipped\%20Instruction

[13] Saltman, D. (2011, November/December). Flipping for beginners: Inside the new classroom craze. Retrieved from: http://hepg.org/hel/article/517

[14] Strayer, J. (2012). How learning in an inverted classroom influences cooperation, innovation and task Orientation. Learning Environments, 15(2), 171.

[15] Craig McBride (2015) Personal website. Retrieved from https://sites.google.com/site/drcraigmcbridephd/ 